\title{
FERMENTASI GLUKOSA HASIL HIDROLISIS BUAH KUMBI UNTUK BAHAN BAKU BIOETANOL
}

\author{
Sri Seno Handayani, Surya Hadi, Haryanti Patmala \\ Program Studi Kimia, Fakultas Matematika dan Ilmu Pengetahuan Alam, \\ Universitas Mataram. Jl. Majapahit 62 Mataram 83125 \\ Email:ninikhandayani09@gmail.com
}

\begin{abstract}
Abstrak. Kumbi atau Voacanga foetida (blume) rolfe merupakan tumbuhan dari family Apocynaceae. Pulau Lombok merupakan daerah utama tempat tumbuhnya 'Kumbi' ini. Kumbi memiliki kandungan selulosa yang cukup tinggi. Selulosa merupakan salah satu bahan baku dalam pembuatan bioetanol. Sebelumnya telah dilakukan penelitian mengenai pembuatan bioetanol dari buah Kumbi (Voacanga foetida (blume) rolfe) ini dengan kadar 14\% dan $\%$ rendemen sebesar 14,793\%. Hasil yang didapatkan ini sudah cukup tinggi namun belum memenuhi syarat untuk dijadikan sebagai bahan baku campuran pada bahan bakar. Tujuan dari penelitian ini untuk mengetahui pengaruh suhu fermentasi terhadap rendemen bioetanol dari buah kumbi menggunakan Saccharomyces cerevisiae dan Rhyzopus oryzae. Metode yang digunakan adalah hidrolisis dengan $\mathrm{HCl}$ dan fermentasi menggunakan Saccharomyces cerevisiae dan Rhyzopus oryzae. Berdasarkan penelitian yang telah dilakukan, bioetanol dari buah kumbi dapat diproduksi melalui proses hidrolisis dan fermentasi menggunakan Saccharomyces cerevisiae dan Rhyzopus oryzae dengan variasi suhu fermentasi $28^{\circ} \mathrm{C}, 30^{\circ} \mathrm{C}, 32^{\circ} \mathrm{C}, 34^{\circ} \mathrm{C}, 36^{\circ} \mathrm{C}, 38^{\circ} \mathrm{C}$ dan $40^{\circ} \mathrm{C}$, dan destilasi pada suhu $78{ }^{\circ} \mathrm{C}$, menghasilkan rendemen bioetanol kasar pada suhu optimum $36{ }^{\circ} \mathrm{C}$ sebesar 66,02\% (w/w) menggunakan Saccharomyces cerevisiae sedangkan dengan rasio yang sama menggunakan Rhyzopus oryzae suhu optimum dicapai pada $32^{\circ} \mathrm{C}$, menghasilkan rendemen bioetanol kasar sebesar $88,14 \%(\mathrm{w} / \mathrm{w})$.
\end{abstract}

\section{Kata kunci: Bioetanol, Buah Kumbi, Hidrolisis, Fermentasi}

Abstract. Kumbi or Voacanga foetida (blume) Rolfe is a plant of the family Apocynaceae. Lombok Island is the main area where the growth of Kumbi. Kumbi has a high cellulose content. Cellulose is a raw material in the manufacture of bioethanol. Research for bioethanol production from fruit Kumbi (Voacanga foetida (blume) Rolfe) generates yield of $14.793 \%$. These results are not yet eligible to be used as raw material in the fuel mixture. This study aims to determine the effect of temperature on the yield of bioethanol fermentation of fruit Kumbi using Saccharomyces cerevisiae and Rhyzopus oryzae. The method used is by $\mathrm{HCl}$ hydrolysis and fermentation with Saccharomyces cerevisiae and Rhyzopus oryzae. The results showed that ethanol from Kumbi fruit can be produced by the hydrolysis and fermentation using Saccharomyces cerevisiae and Rhyzopus oryzae. Fermentation temperature variation used was $28{ }^{\circ} \mathrm{C}, 30{ }^{\circ} \mathrm{C}, 32{ }^{\circ} \mathrm{C}, 34{ }^{\circ} \mathrm{C}, 36{ }^{\circ} \mathrm{C}, 38{ }^{\circ} \mathrm{C}, 40{ }^{\circ} \mathrm{C}$ and distilled at a temperature of 78 C. The yield of bioethanol $66.02 \%$ (w/w ) obtained using Saccharomyces cerevisiae at a temperature of $36{ }^{\circ} \mathrm{C}$ while the same ratio used Rhyzopus oryzae produce bioethanol yield of $88.14 \%$ (w / w) at a temperature of $32{ }^{\circ} \mathrm{C}$.

Keywords: Bioethanol, Fruit Kumbi, hydrolysis, fermentation

\section{PENDAHULUAN}

Kumbi (Voacanga foetida (B1.) Rolfe) merupakan tumbuhan dari family Apocynaceae yang terdistribusi merata diseluruh Indonesia. Namun, Lombok merupakan daerah utama tempat tumbuhnaya 'Kumbi' ini. Kumbi memiliki pertumbuhan yang relatif cepat dan dapat tumbuh pada berbagai kondisi serta selalu berbuah tanpa mengenal musim.

Buah kumbi mengandung selulosa yang cukup tinggi. Tumbuhan ini memiliki kandungan selulosa sebesar 30,1 \% [1]. Selulosa merupakan salah satu bahan baku dalam pembuatan bioetanol. Etanol adalah salah satu bahan bakar alternatif yang dapat diperbaharui, ramah lingkungan, serta menghasilkan gas emisi karbon yang rendah dibandingkan dengan bensin atau sejenisnya (sampai $85 \%$ lebih rendah) sehingga dapat dijadikan alternatif pengganti bahan bakar mineral yang jumlanya semakin menipis [2].

Pada penelitian sebelumnya, didapatkan bioetanol dari buah Kumbi (Voacanga foetida (B1.) Rolfe) ini dengan \% rendemen sebesar 14,793\% [1].
Hasil yang didapatkan ini sudah cukup tinggi namun belum memenuhi syarat untuk dijadikan sebagai bahan baku campuran pada bahan bakar. Bioetanol sebagai bahan pencampur bahan bakar ini harus benar-benar kering dan anhydrous untuk mencegah terjadinya korosi pada mesin kendaraan [1].

Oleh sebab itu, perlu dilakukan penelitian lebih lanjut mengenai pembuatan bioetanol dari buah kumbi ini. Untuk meningkatkan kadar bioetanol dari buah Kumbi (Voacanga foetida (Bl.) Rolfe) ini dapat dilakukan optimasi pada proses pembuatan bioetanol. Salah satu proses yang sangat penting dari pembuatan bioetanol adalah proses fermentasi. Pada proses ini terjadi perombakan molekul-molekul glukosa menjadi alkohol oleh yeast (ragi). Ada beberapa faktor yang mempengaruhi proses ini, salah satunya adalah suhu fermentasi. Suhu selama proses fermentasi sangat menentukan jenis mikroorganisme dominan yang akan tumbuh [3]. Mikroorganisme mempunyai temperatur maksimal dan optimal untuk pertumbuhannya. 
Temperatur optimal untuk yeast berkisar antara $25-30^{\circ} \mathrm{C}$ dan temperatur maksimal antara $35-47^{\circ} \mathrm{C}$. Temperatur selama fermentasi perlu mendapatkan perhatian, karena di samping temperatur mempunyai efek yang langsung terhadap pertumbuhan ragi juga mempengaruhi komposisi produk akhir.

\section{METODE PENELITIAN}

Bahan yang digunakan adalah aquadest, $\mathrm{HCl}$, etanol, larutan glukosa, urea, $\mathrm{KH}_{2} \mathrm{PO}_{4}$, ragi tempe (Rhyzopus oryzae) dan ragi roti (Saccharomyces cerevisiae). Peralatan yang digunakan adalah alat gelas, rotary evaporator, shaker bath, penangas air, Spektrofotometer GC-MS dan Spektrofotometer UVVis.

\section{Preparasi Sampel}

Buah kumbi dibersihkan, lalu dipotong kecilkecil dan dioven dengan suhu $105^{\circ} \mathrm{C}$. Selanjutnya diblender dan diayak untuk memperkecil ukurannya agar lebih mudah pada proses selanjutnya.

\section{Pengukuran Kadar Air}

Kadar air ditetapkan dengan metode oven. Satu biji utuh dikupas bersih dan dipotong kecil-kecil untuk kemudian ditimbang lalu dioven selama 2 jam dengan suhu $105^{\circ} \mathrm{C}$. Didinginkan dalam desikator selama 15 menit. Sampel yang sudah kering lalu ditimbang. Pengeringan dilakukan berulang-ulang hingga didapatkan berat kering yang konstan.

\section{Analisis Kadar Selulosa}

Sebanyak 3 gram sampel kering dimasukkan ke dalam gelas kimia $250 \mathrm{ml}$. Sampel dibasakan dengan $15 \mathrm{ml} \mathrm{NaOH} \mathrm{17,5 \%} \mathrm{dan} \mathrm{dimaserasi} \mathrm{selama} 1$ menit, lalu

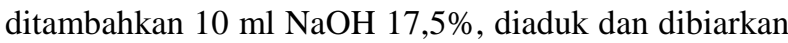
selama 3 menit. Kemudian ditambahkan kembali $3 \times 10$ $\mathrm{ml} \mathrm{NaOH} \mathrm{17,5 \%} \mathrm{setiap} \mathrm{2,5;} 5$; 7,5 menit dan dibiarkan selama 30 menit. Setelah itu ditambahkan $100 \mathrm{ml}$ aquades dan dibiarkan selama 30 menit, lalu campuran disaring dan endapan dicuci dengan $5 \times 50 \mathrm{ml}$ aquades. Kertas saring yang berisi endapan dipindahkan ke gelas kimia dan dicuci kembali dengan $400 \mathrm{ml}$ aquades, ditambahkan $10 \mathrm{ml}$ asam asetat glasial $2 \mathrm{~N}$ dan diaduk selama 5 menit. Endapan disaring dan dikeringkan dalam oven dengan suhu $105{ }^{\circ} \mathrm{C}$, kemudian didinginkan dalam desikator dan ditimbang hingga berat konstan

\section{Analisis Kadar Lignin}

Sampel ditimbang sebanyak 2 gram kemudian dimasukkan dalam gelas kimia dan ditambahkan sedikit demi sedikit dengan $40 \mathrm{~mL}$ asam sulfat $72 \%$ sambil diaduk sampai semua sampel terendam dan terdispersi. Setelah terdispersi, gelas kimia ditutup dan dijaga pada temperature $20^{\circ} \mathrm{C}$ selama 2 jam kemudian ditambahkan $400 \mathrm{~mL}$ aquades kedalam gelas kimia, larutan didihkan selama 4 jam dalam gelas kimia, kemudian didiamkan sampai endapan lignin mengendap kemudian endapan lignin disaring untuk mendapatkan lignin. Lignin dicuci dengan air panas lalu dikeringkan dalam oven dan setelah kering didinginkan didalam desikator dan ditimbang tiap 15 menit sampai berat lignin konstan.

\section{Hidrolisis Buah Kumbi dengan HCl 2\%}

Buah kumbi yang telah dihaluskan ukurannya, ditimbang $25 \mathrm{~g}$ lalu dihidrolisis dengan $200 \mathrm{ml} \mathrm{HCl} 2 \%$ pada suhu $70^{\circ} \mathrm{C}$ selama $1,5 \mathrm{jam}$ dalam penangas air.

\section{Uji Kadar Gula Reduksi (Metode Nelson-Somogyi)}

Penentuan kadar glukosa dalam sampel dengan menggunakan metode ini yaitu melalui reduksi ion $\mathrm{Cu}^{2+}$ oleh glukosa sehingga membentuk endapan merah bata $\mathrm{Cu}_{2} \mathrm{O}$ dengan penambahan arsenomolibdat akan membentuk warna biru yang kemudian akan ditentukan kadarnya melalui spektrofotometer pada panjang gelombang maksimal. Nilai absorbansinya akan berhubungan dengan kadar glukosa dalam sampel.

\section{Fermentasi}

Proses fermentasi dilakukan dengan menimbang larutan hidrolisat sebanyak 2x50 gram, masing-masing diletakkan pada erlenmeyer yang berbeda, kemudian pada erlenmeyer pertama ditambahkan dengan 10 gram ragi roti (Saccharomyces cerevisiae) sedangkan pada erlenmeyer kedua ditambahkan dengan 10 gram ragi tempe (Rhyzopus oryzae), pada kedua erlenmeyer tersebut ditambahkan msing-masing 4 gram urea dan 4 gram $\mathrm{KH}_{2} \mathrm{PO}_{4}$. Lalu ditambahkan dengan $250 \mathrm{ml}$ aquades. Larutan yang akan difermentasi diatur pHnya menjadi $\mathrm{pH} 4$ dengan penambahan $\mathrm{NaOH}$ 1M. Setelah larutan mencapai $\mathrm{pH}$ yang diinginkan, larutan ditutup rapat dan dishaker selama 24 jam dengan suhu yaitu $28^{\circ} \mathrm{C}$, lalu didiamkan dalam ruang gelap selama 6 hari pada suhu ruang. Proses fermentasi dilakukan kembali dengan variasi suhu yaitu $30^{\circ} \mathrm{C}, 32^{\circ} \mathrm{C}, 34^{\circ} \mathrm{C}, 36^{\circ} \mathrm{C}, 38^{\circ} \mathrm{C}$, dan $40^{\circ} \mathrm{C}$.

\section{Destilasi}

Hasil fermentasi disaring, lalu filtratnya dimasukkan ke dalam alat destilasi, kemudian didestilasi dengan suhu $78-80^{\circ} \mathrm{C}$ selama 1,5 jam.

\section{Analisis GC-MS}

Bioetanol hasil destilasi dianalisis pola kromatogramnya dengan menggunakan GC-MS.

\section{HASIL DAN PEMBAHASAN}

Proses pembuatan bioetanol dilakukan melalui beberapa tahapan, yaitu preparasi sampel, proses hidrolisis, proses fermentasi, pemurnian atau destilasi, dan analisis kadar bioetanol yang dihasilkan.

\section{Preparasi Sampel}

Dari buah kumbi yang dipreparasi, didapatkan komposisi dan komponen buah kumbi seperti pada tabel 1.1. 
Tabel 1.1Komposisi dan Komponen Buah Kumbi

\begin{tabular}{lc}
\hline Parameter & Persentase $(\%)$ \\
\hline Buah kumbi utuh & - \\
Daging buah basah & 83,5764 \\
Daging buah kering & 8,9691 \\
Kulit buah & 10,1812 \\
Biji buah & 3,8338 \\
Kadar air & 89,2678 \\
Selulosa & 24,2467 \\
Lignin & 5,005 \\
\hline
\end{tabular}

\section{Hidrolisis Buah Kumbi dengan HCl 2\%}

Hidrolisis selulosa dapat dilakukan secara enzimatis dan kimiawi. Hidrolisis secara enzimatis dapat dilakukan dengan menggunakan enzim selulase, sedangkan hidrolisis secara kimiawi dapat dilakukan dengan menggunakan asam, yaitu asam kuat konsentrasi rendah maupun asam lemah konsentrasi tinggi. Umumya asam yang digunakan adalah $\mathrm{H}_{2} \mathrm{SO}_{4}$ atau $\mathrm{HCl}$ [4] pada range konsentrasi 2-3\% [5]

Pada penelitian ini digunakan katalisator berupa asam kuat yaitu $\mathrm{HCl} 2 \%$. Menurut Osvaldo [6], konsentrasi asam 2\% menghasilkan kadar alkohol tertinggi yaitu 5,0675\%. Pemilihan ini didasarkan bahwa garam yang terbentuk setelah penetralan hasil merupakan garam yang tidak berbahaya yaitu garam dapur [7]. Selain itu, $\mathrm{HCl}$ digunakan sebagai katalis karena merupakan salah satu oksidator kuat, lebih aman jika dibandingkan dengan asam yang lain $\left(\mathrm{HNO}_{3}\right.$ dan $\mathrm{H}_{2} \mathrm{SO}_{4}$ ), dan lebih mudah didapatkan. Dalam penelitian ini tidak digunakan metode enzimatis karena metode enzimatis memiliki kelemahan seperti sulitnya isolasi enzim yang sesuai, tidak dapat digunakan kembali, dan stabilitas termal yang rendah sehingga akan menaikkan biaya produksi [8].

Hidrolisis dalam suasana asam menghasilkan pemecahan ikatan glikosida dan berlangsung dalam tiga tahap. Tahap pertama proton yang bertindak sebagai katalisator asam berinteraksi cepat dengan oksigen glikosida yang menghubungkan dua unit gula (I), yang akan membentuk asam konjugat (II). Langkah ini akan diikuti dengan pemecahan yang lambat dari ikatan C-O, dalam kebanyakan hal menghasilkan zat antara kation karbonium siklis (III). Protonasi dapat juga terjadi pada oksigen cincin (II'), menghasilkan pembukaan cincin dan kation karbonium non siklis (III') [4]. Mekanisme reaksi total hidrolisis selulosa secara asam ditampilkan dibawah ini :

Persamaan regresi yang diperoleh dari kurva glukosa standar yaitu $y=0,0058 x+0,0122$. Berdasarkan persamaan tersebut kita akan dapat menghitung kadar glukosa hasil hidrolisis berdasarkan absorbansi yang diperoleh. Hasil pengukuran nilai absorbansi dari sampel buah kumbi sebesar 0,371. Nilai absorbansi tersebut dimasukkan ke dalam persamaan regresi untuk menghitung kadar glukosa. Adapun nilai kadar glukosa pada sampel kering buah kumbi yang didapatkan dari perhitungan adalah sebesar 7,18 g/L.
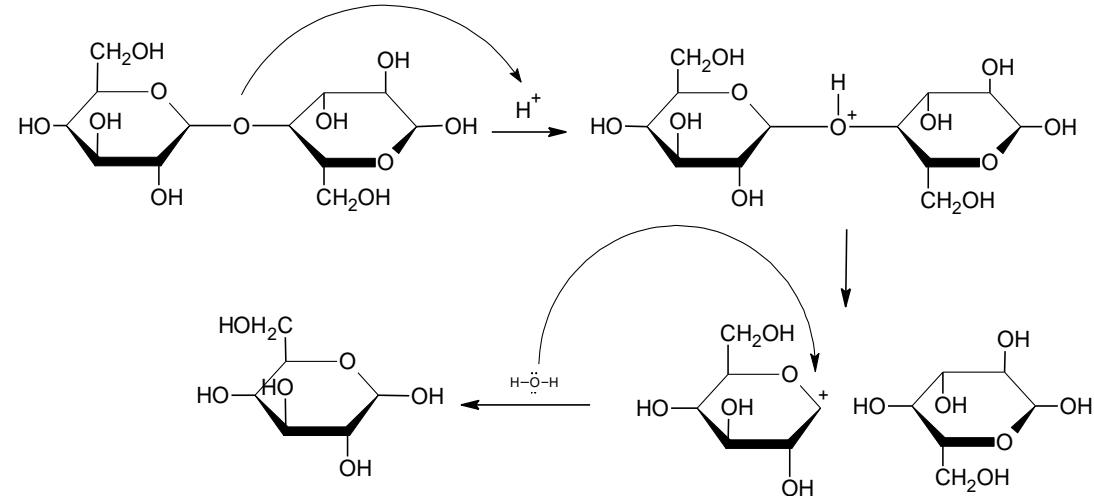

Gambar 1.1 Reaksi Hidrolisis Secara Asam

\section{Fermentasi}

Dalam penelitian ini digunakan dua jenis mikroba yang berbeda yaitu khamir jenis Saccharomyces cerevisiae dan kapang jenis Rhyzopus oryzae.

Dilakukan dua tahap fermentasi yaitu pada 24 jam pertama dilakukan proses agitasi menggunakan water bath shaker dengan tujuan untuk meningkatkan kontak antara mikroba dengan nutrisi yang ditambahkan kedalam substrat sehingga tersuspensi dengan homogen. Pada proses agitasi dilakukan variasi suhu yaitu $28^{\circ} \mathrm{C}, 30^{\circ} \mathrm{C}, 32^{\circ} \mathrm{C}, 34^{\circ} \mathrm{C}, 36^{\circ} \mathrm{C}, 38^{\circ} \mathrm{C}$ dan $40^{\circ} \mathrm{C}$ untuk mengetahui pengaruh suhu pada fase lag (adaptasi) terhadap rendemen bioetanol yang dihasilkan pada pembuatan bioetanol dari buah kumbi (Voacanga foetida (B1.) Rolfe) ini.
Setelah dilakukan proses agitasi selama 24 jam, proses fermentasi dilanjutkan dengan penyimpanan didalam ruang tertutup pada suhu kamar selama 6 hari. Pada waktu fermentasi terjadi kenaikan panas, karena reaksinya eksoterm. Untuk mencegah agar suhu fermentasi tidak naik, perlu pendingin agar dipertahankan tetap $26-30^{\circ} \mathrm{C}$. Dalam proses fermentasi terjadi reaksi pembentukan alkohol jenis etanol seperti yang ditunjukkan persamaan berikut :

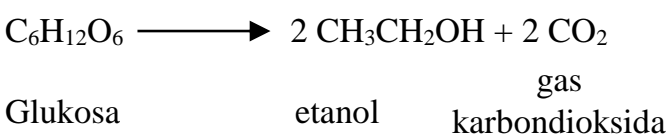

Gambar 1.2 Proses Pembentukan Alkohol 
Menurut Martoharsono [9], pembentukan bioetanol dari glukosa melalui proses fermentasi berlangsung melalui dua tahap yaitu tahap glikolisis dan tahap fermentasi alkohol. Pada tahap awal, karbohidrat akan dipecah dahulu menjadi gula sederhana yaitu dengan hidrolisis pati menjadi unit-unit glukosa.

Dalam tahap pertama fermentasi glukosa selalu terbentuk asam piruvat melalui jalur Embden Meyerhof Parnas (EMP) atau glikolisis. Glikolisis merupakan rangkaian reaksi kimia penguraian glukosa (yang mempunyai 6 atom C) menjadi asam piruvat (yang mempunyai 3 atom $\mathrm{C}$ ), $\mathrm{NADH}$ dan ATP. NADH (Nikotinamida Adenina Dinukleotida Hidrogen) adalah koenzim yang mengikat elektron $(\mathrm{H})$, sehingga disebut elektron berenergi tinggi. ATP (Adenosin Trifosfat) merupakan senyawa berenergi tinggi. Setiap pelepasan fosfatnya menghasilkan energi. Pada proses glikolisis, setiap 1 molekul glukosa diubah menjadi 2 molekul asam piruvat, 2 NADH, dan 2 ATP.

Pada tahap kedua yaitu fermentasi alkohol, piruvat tersebut diubah menjadi alkohol melalui dua tahap yaitu pertama, piruvat didekarboksilasi menjadi asetaldehid oleh piruvat dekarboksilase dengan melibatkan tiamin pirofosfat dan tahap kedua asetaldehid oleh alkohol dehidrogenase direduksi dengan $\mathrm{NADH}_{2}$ menjadi alkohol [10]. Proses fermentasi dapat dilihat pada gambar dibawah ini:

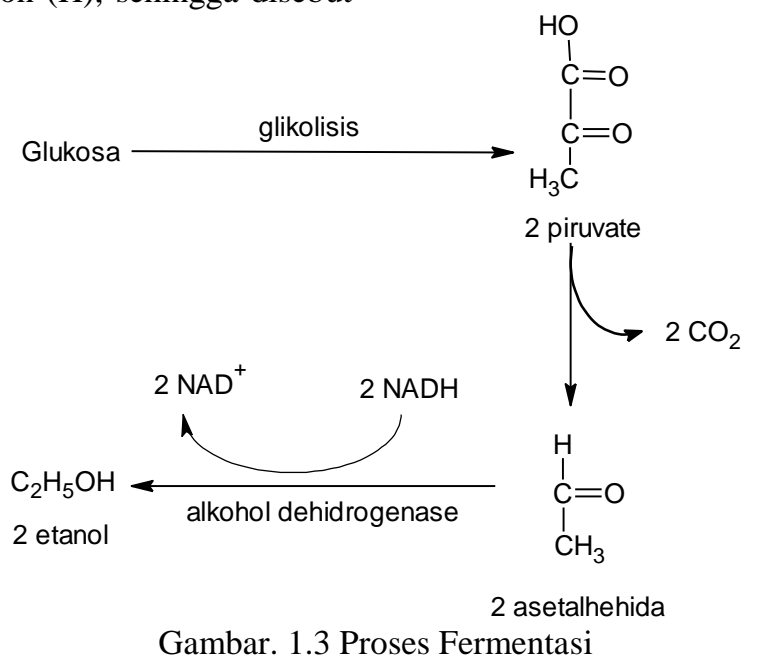

\section{Destilasi}

Bioetanol yang dihasilkan dari proses fermentasi ini masih mengandung gas $\mathrm{CO}_{2}$ sehingga untuk mendapatkan bioetanol dengan kualitas yang lebih baik perlu dilakukan penyaringan untuk memisahkan bioetanol dari gas $\mathrm{CO}_{2}$ tersebut. Proses pembersihan $\mathrm{CO}_{2}$ dilakukan dengan menyaring bioetanol yang terikat oleh $\mathrm{CO}_{2}$, sehingga dapat diperoleh bioetanol yang bersih dari gas $\left(\mathrm{CO}_{2}\right)$.

Kadar alkohol yang dihasilkan dari proses fermentasi, biasanya hanya mencapai $8-10 \%$ saja, sehingga untuk memperoleh etanol yang berkadar alkohol $95 \%$ diperlukan proses lainnya, yaitu proses destilasi. Oleh karena itu, dilakukan destilasi pada titik didih etanol yaitu $78^{\circ} \mathrm{C}$. Dengan memanaskan larutan pada suhu rentang $78-90^{\circ} \mathrm{C}$ akan mengakibatkan sebagian besar etanol menguap. Proses distilasi akan meningkatkan kandungan ethanol hingga 95\% (Jannah,2010).

Dari hasil fermentasi dan destilasi (pemurnian) bioetanol menggunakan mikroba Saccharomyces cereviceae dengan variasi suhu $28^{\circ} \mathrm{C}, 30^{\circ} \mathrm{C}, 32^{\circ} \mathrm{C}$, $34^{\circ} \mathrm{C}, \quad 36^{\circ} \mathrm{C}, \quad 38^{\circ} \mathrm{C}$ dan $40^{\circ} \mathrm{C}$ pada saat agitasi didapatkan rendemen kotor bioetanol sebagai berikut :
Tabel 4.4. Rendemen Bioetanol Kasar (crude) Menggunakan Saccharomyces cerevisiae

\begin{tabular}{lcc}
\hline No & $\begin{array}{c}\text { Suhu Fermentasi } \\
\left({ }^{\circ} \mathrm{C}\right)\end{array}$ & $\begin{array}{c}\% \\
\text { Rendemen }\end{array}$ \\
\hline 1. & 28 & 21,74 \\
2. & 30 & 22,66 \\
3. & 32 & 23,12 \\
4. & 34 & 28,72 \\
5. & 36 & 66,02 \\
6. & 38 & 6,30 \\
7. & 40 & 0 \\
\hline
\end{tabular}

Dari tabel diatas dapat dilihat bahwa, variasi suhu pada proses awal fermentasi yaitu 24 jam pertama memberikan pengaruh terhadap rendemen bioetanol yang dihasilkan. Rendemen bioetanol tertinggi dihasilkan pada suhu $36^{\circ} \mathrm{C}$, sehingga dapat dikatakan bahwa suhu optimum untuk proses awal pada fermentasi pembuatan bioetanol dari buah kumbi (Voacanga foetida (Bl.) Rolfe) dengan menggunakan mikroba Saccharomyces cereviceae adalah $36^{\circ} \mathrm{C}$. Kenaikan suhu ini berpengaruh baik terhadap proses fermentasi karena aktivitas khamir memfermentasi substrat meningkat seiring dengan peningkatan suhu sampai batas tertentu. Kenaikan suhu sampai batas tertentu juga akan mempercepat laju reaksi karena semua reaksi enzimatik dipengaruhi suhu [11]. 
Sedangkan dari hasil fermentasi bioetanol menggunakan mikroba Rhyzopus orizae dengan variasi suhu $28^{\circ} \mathrm{C}, 30^{\circ} \mathrm{C}, 32^{\circ} \mathrm{C}, 34^{\circ} \mathrm{C}, 36^{\circ} \mathrm{C}, 38^{\circ} \mathrm{C}$ dan $40^{\circ} \mathrm{C}$ didapatkan rendemen bioetanol kasar (crude bioethanol) sebagai berikut :

Tabel 4.5. Rendemen Bioetanol Kasar (crude) Menggunakan Rhyzopus oryzae

\begin{tabular}{lcc}
\hline No. & $\begin{array}{c}\text { Suhu Fermentasi } \\
\left({ }^{\circ} \mathrm{C}\right)\end{array}$ & \% Rendemen \\
\hline 1. & 28 & 74,64 \\
2. & 30 & 85,44 \\
3. & 32 & 88,14 \\
4. & 34 & 42,70 \\
5. & 36 & 36,10 \\
6. & 38 & 11,62 \\
7. & 40 & 2,06 \\
\hline
\end{tabular}

Dari tabel di atas dapat dilihat bahwa, rendemen bioetanol tertinggi dihasilkan pada suhu $32^{\circ} \mathrm{C}$, sehingga dapat dikatakan bahwa suhu optimum yang digunakan pada proses awal fermentasi pembuatan bioetanol dari buah kumbi (Voacanga foetida (B1.) Rolfe) dengan menggunakan mikroba Rhyzopus oryzae ini adalah $32^{\circ} \mathrm{C}$. Sama halnya dengan Saccharomyces cerevisia, proses adaptasi kapang Rhyzopus oryzae juga dipengaruhi oleh suhu agitasi diawal proses fermentasi. Menurut Rahayu dan Rahayu [11], kenaikan suhu ini berpengaruh baik terhadap proses fermentasi karena aktivitas khamir memfermentasi substrat meningkat seiring dengan peningkatan suhu sampai batas tertentu. Kenaikan suhu sampai batas tertentu juga akan mempercepat laju reaksi karena semua reaksi enzimatik dipengaruhi suhu.

Berdasarkan hasil diatas, dapat dilihat bahwa fermentasi dengan khamir Saccharomyces cerevisiae dan kapang Rhyzopus orizae dengan variasi suhu pada proses awal fermentasi yang sama yaitu $28^{\circ} \mathrm{C}, 30^{\circ} \mathrm{C}$, $32^{\circ} \mathrm{C}, 34^{\circ} \mathrm{C}, 36^{\circ} \mathrm{C}, 38^{\circ} \mathrm{C}$ dan $40^{\circ} \mathrm{C}$ memiliki suhu optimum yang berbeda yaitu $36^{\circ} \mathrm{C}$ menggunakan Saccharomyces cerevisiae dan $32^{\circ} \mathrm{C}$ menggunakan Rhyzopus orizae. Adanya perbedaan suhu optimum ini disebabkan oleh masing-masing jenis mikroorganisme memiliki suhu pertumbuhan yang berbeda-beda. Dari data diatas dapat diketahui bahwa fermentasi menggunakan Rhyzopus orizae mampu menghasilkan kadar etanol lebih tinggi dibandingkan dengan fermentasi menggunakan Saccharomyces cerevisiae. Hal ini sesuai dengan hasil penelitian Karimi [12], yang menyatakan bahwa $M$. indicus dan $R$. oryzae merupakan alternatif ragi yang baik dalam pembuatan roti. Fungi berfilamen ini mampu memproduksi etanol dengan kadar etanol lebih tinggi daripada $S$. cerevisiae pada periode waktu yang sama. Menurut Karimi [12], fungi memiliki keuntungan lebih dari $S$. cerevisae. Dimana fungi dapat tumbuh pada suhu lebih tinggi dari $S$. cerevisae. Selain itu, suhu optimum sakarifikasi dan fermentasi fungi lebih rendah daripada menggunakan $S$. cerevisiae. Hal ini dapat menjadi alasan mengapa didapatkan yield bioetanol lebih tinggi dengan menggunakan $R$. oryzae dibandingkan dengan menggunakan $S$. cerevisiae.

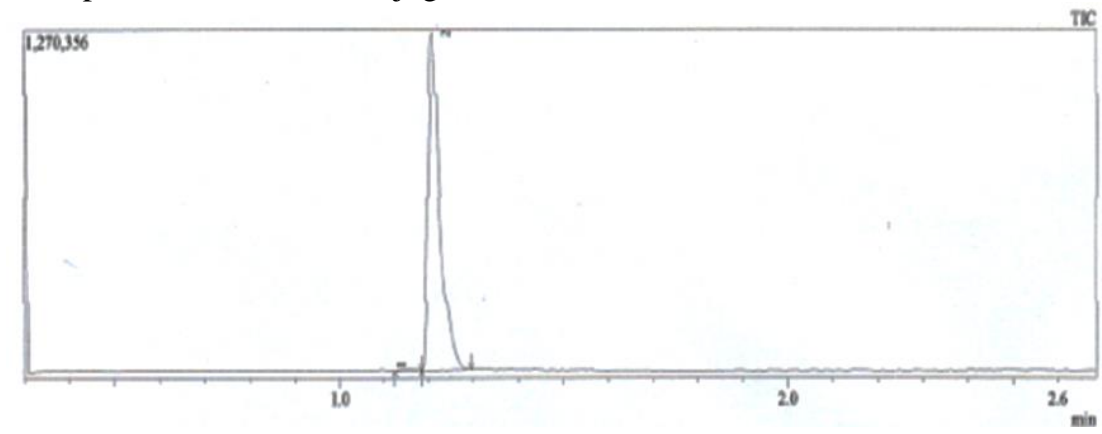

Gambar. 1.4. Hasil Analisis GC-MS Bioetanol dengan Rhyzopus oryzae pada Suhu $28^{\circ} \mathrm{C}$

\section{Analisis GC-MS}

Dari hasil analisis GC-MS, dapat diketahui bahwa ethanol adalah produk utama dalam pembuatan bioetanol dari proses fermentasi hidrolisat kumbi menggunakan ragi roti (Saccharomyces cerevisiae) dengan persentase kemurnian bioethanol yang dihasilkan sebesar 91,70\%. Sedangkan menggunakan ragi roti (Rhyzopus oryzae) didapatkan persentase kemurnian bioethanol yang dihasilkan sebesar $99,10 \%$.

Selain menghasilkan etanol juga menghasilkan metanol. Hal ini disebabkan oleh ragi roti dan ragi tempe tidak hanya mengandung Saccharomyces cereviceae atau Rhyzopus orizae, namun juga mengandung Archaebacteria methanogen yang mampu menghasilkan metanol dalam metabolisme energinya, serta Acetobacter yang dapat mengubah alkohol menjadi asam asetat. Hal inilah yang dapat menyebabkan kadar etanol dari destilat hasil fermentasi rendah, selama proses fermentasi berlangsung genus dari Acetobacter terus melakukan perombakan alkohol menjadi asam asetat.

\section{Kesimpulan}

Berdasarkan hasil dari penelitian ini, dapat ditarik kesimpulan bahwa : 
a. Buah kumbi (Voacanga foetida (blume) rolfe) berpotensi sebagai bahan baku pembuatan bioetanol karena mengandung selulosa sebanyak 24,2467\% (w/w).

b. Suhu optimum untuk pembuatan bioetanol buah kumbi melalui proses hidrolisis dan fermentasi menggunakan yeast Saccharomyces cerevisiae adalah $36^{\circ} \mathrm{C}$, yaitu mampu menghasilkan 66,02\% bioetanol kasar. Sedangkan, dengan menggunakan yeast Rhyzopus orizae, didapatkan suhu optimum pada $32^{\circ} \mathrm{C}$, yaitu mampu menghasilkan $88,14 \%$ bioetanol kasar.

c. Berdasarkan analisis GC-MS, diketahui senyawa puncak dasar ion molekul $\left(\mathrm{M}^{+}\right)$dengan $\mathrm{m} / \mathrm{z}=45$ menunjukkan bahwa senyawa tersebut adalah etanol. Dimana, tingkat kemurnian bioetanol yang terbentuk dari hasil fermentasi menggunakan Saccharomyces cerevisiae adalah 91,70\%. Sedangkan tingkat kemurnian bioetanol yang terbentuk menggunakan Rhyzopus orizae adalah $99,10 \%$.

\section{DAFTAR PUSTAKA}

[1]. Ayuarni, Sri Puji.2014. Pembuatan Bioetanol dari Buah Kumbi (Voacanga Foetida (Bi.) Rolfe) dengan Metode Fermentasi melalui Hidrolisis. Mataram : Universitas Mataram.

[2]. Prihandana, Sri Komarayati. 2007. Bioetanol Ubi kayu Bahan Bakar Masa Depan.Jakarta: Agromedia.

[3]. Effendi, M.S. 2002. Kinetika Fermentasi Asam Asetat (Vinegar) oleh Bakteri Acetobacter aceti B127 dari Etanol Hasil Fermentasi Limbah Cair Pulp Kakao. J Teknol Ind Pert 13:125-135.

[4]. Oktavianus, Ferdin., dkk. 2013. Pembuatan Bioetanol dari Batang Jarak Menggunakan Metode Hidrolisa dengan Katalis asam Sulfat. Jurnal Teknik Kimia, 2, 19.

[5]. Iranmahboob.,et al. 2002. Optimizing Acid Hydrolysis : A Critical Step for Production of Ethanol from Mixed Wood Chips. Biomass And Bioenergy, 22: 401-404

[6]. Osvaldo, Z. S., dkk. 2012. Pengaruh Konsentrasi Asam dan Waktu pada Proses Hidrolisis dan fermentasi Pembuatan Bioetanol dari Alang-Alang. Jurnal teknik Kimia, 2, 18.

[7]. Endah, R D., Sperisa D., Adrian Nur, dan Paryanto.2007.Pengaruh Kondisi Fermentasi Terhadap Yield Etanol pada Pembuatan Bioetanol dari Pati Garut. Surakarta:Universitas Sebelas maret.

[8]. Rodiansono, dkk. 2013. Hidrolisis Lignoselulosa dari Tandan Kelapa Sawit Menggunakan Katalis Asam Karboksilat. Banjarbaru: Universitas Lambung Mangkurat.

[9]. Martoharsono, S.1986. Biokimia, Jilid II. Yogjakarta: Gajah Mada University Press.
[10]. Sutiari. 1983. Produksi Alkohol dari Daging dan Kulit Pisang. Malang: Universitas Brawijaya.

[11]. Rahayu, Tuti dan Rahayu, Triastuti. 1988. Optimasi Fermentasi Cairan Kopi dengan Inokulan Kultur Kombucha (Kombuchaa Coffe).Jurnal Penelitian Sains dan Tekhnologi, 8, 1, 15-29. UMS: Surakarta.

[12]. Karimi, Keikhosro., et. al. 2006. Ethanol Producting from Dilute-Acid Pretreated Rice Straw by Simultanious Saccarification and Fermentation with Mucor Indicus, Rhyzopus oryzae, and Saccharomyces cerevisiae. Enzym and Microbial Technology 40, 138-144.

[13]. Winarno. F.G., 1980. Kimia Pangan dan Gizi. Jakarta : Gramedia Pustaka Utama 